\title{
Sandfly Lutzomyia longipalpis in a Cutaneous Leishmaniasis Focus in Central Colombia
}

\author{
Yolanda López ${ }^{+}$, Lisardo Osorio, Gilberto Alvarez, Jaime Rojas*, \\ Fernando Jiménez*, Carmen Gómez*, Cristina Ferro**
}

Grupo de Entomología, Laboratorio Departamental de Salud Pública, Dirección Seccional de Salud de Antioquia, Carrera 51A Nº 62-42, Medellín, Colombia *Servicio Seccional de Salud de Antioquia (Hospitales de Puerto

Triunfo y Rionegro) **Laboratorio de Entomología, Instituto Nacional de Salud, Avenida el Dorado con

Carrera 50, Santafé de Bogotá, Colombia

Lutzomyia longipalpis, 15 other species of the genus Lutzomyia, and one species of Brumptomyia were collected in an endemic focus of cutaneous leishmaniasis in a river canyon $450 \mathrm{~m}$ above sea-level, in Rio Claro, Antioquia, Colombia. The presence of Lu. longipalpis is associated with the destruction of the primary forest and the development of new farmland and rural settlement in this region. The composition of species identified a different habitat for Lu. longipalpis in Colombia. Lu. yuilli and Lu. longipalpis were predominant (68.26\%) followed by Lu. trapidoi, Lu. hartmani, Lu. triramula, Lu. panamensis, Lu. gomezi.

Key words: Lutzomyia longipalpis - sand fly - ecology - leishmaniasis - Colombia

Lutzomyia longipalpis (Lutz \& Neiva) is the main vector of Leishmania (L.) chagasi, the aetiologic agent of American visceral leishmaniasis (Ward 1985, Shaw \& Lainson 1987, Momen et al. 1987, Grimaldi et al. 1989, Cupolillo et al. 1994, Tesh 1995). This sand fly has a wide geographical distribution in the New World, occurring in tropical areas from Mexico to Argentina (Ward 1985, Young \& Duncan 1994). It has been found in a variety of habitats, from arid areas with rock and xerophytic vegetation to moist, lush forest in the Amazon River Basin (Zeledon et al. 1974, Lainson et al. 1990). A common feature of this sand fly is its propensity to move into the peridomestic environment, particularly in rural and suburban communities where domestic animals and their shelters are present (Lainson 1989).

Recent reports from foci of American cutaneous leishmaniasis in a mountainous region of the State of Ceará, Brazil (Queiroz et al. 1991) and in a periurban site near Rio de Janeiro, Brazil (Rangel et al. 1990) agree with Lainson (1989) and Tesh (1995) that, the neotropics ecologic and demographic changes have led to conditions which now support large populations of the vector $L u$. longipalpis. As a consequence, visceral leishmaniasis occurs now in many regions where it was not found previously. From a public health

${ }^{+}$Corresponding author. Fax: 211-15.99

Received 10 May 1995

Accepted 21 March 1996 perspective, this is one of the most important emerging parasitic diseases (Tesh 1995).

In Colombia, the geographic distribution of visceral leishmaniasis and Lu. longipalpis coincide in the upper and middle Magdalena River Valley, with endemic foci in Huila, Tolima, Cundinamarca and Santander, and has been associated with arid and semi-arid zones, at elevations under $1000 \mathrm{~m}$ at sea level, characterized by scarce vegetation and small gallery forests (Corredor et al. 1990). Other sand flies species, Lu. trinidadensis (Newstead), Lu. cayenensis (Floch \& Abonnec), Lu. atroclavata (Knob) are common in this habitat (Ferro et al. 1995). Despite its ecological similarities with the foci of the Magdalena River Valley, Lu. longipalpis has to date not been collected in the northern focus of Colombia. Lu. evansi (Nuñez-Tovar) has been implicated as an alternative vector of visceral leishmaniasis there (Travi et al. 1990) (Fig. 1).

We report here the results of sand fly collections, carried out in an endemic focus of cutaneous leishmaniasis, which contained Lu. longipalpis. The composition of species identified habitat differences for $\mathrm{Lu}$. longipalpis in Colombia. Moreover, this was an unexpected finding because no cases of visceral leishmaniasis have been reported in this area.

\section{MATERIALS AND METHODS}

Study area - All sand fly collections were made between September 4-5, 1991 in La Mulata and El Refugio $\left(5^{\circ} 53^{\prime} \mathrm{N}, 74^{\circ} 39^{\prime} \mathrm{W}\right)$, in the municipality of San Luis, Departament of Antioquia, Colombia. Both sites are part of the Rio Claro Valley (Fig. 2). 


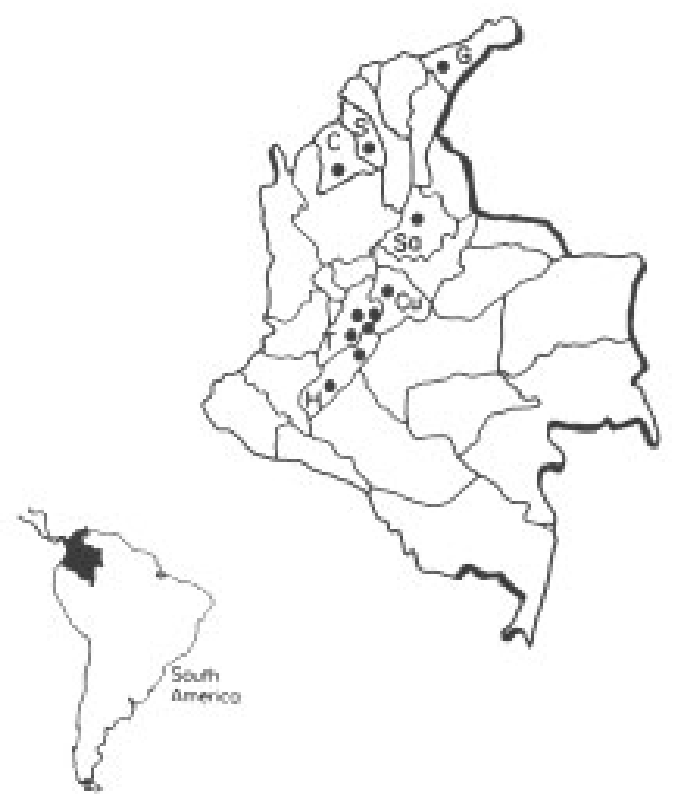

Fig. 1: map of Colombia showing focus of visceral leishmaniasis $(\mathrm{G}=$ Guajira, $\mathrm{C}=$ Córdoba, $\mathrm{S}=$ Sucre, $\mathrm{Cu}=$ Cundinamarca, $\mathrm{Sa}=$ Santander, $\mathrm{T}=$ Tolima, $\mathrm{H}=$ Huila).

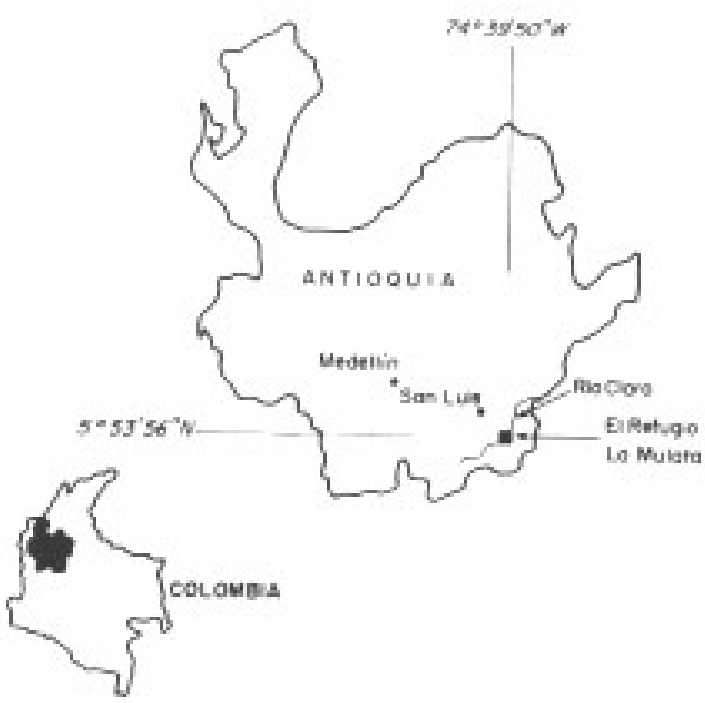

Fig. 2: location of Rio Claro region in department of Antioquia, Colombia.

The Rio Claro valley is classified as humid tropical forest (Espinal et al. 1978), although in the last 10 years the region has been modify by the massive destruction of the forest, rapid human population growth, and the concomitant development of new farmland and rural settlements.

La Mulata, at $500 \mathrm{~m}$ elevation, is a small rural community with 45 inhabitants. The hills encir- cling La Mulata are covered by small patches of forest and agricultural crops, including manioc, pineapple and cocoa. The nine houses in the community are constructed with wooden plank walls that provide easy access to bloodsucking insects.

El Refugio Natural Forest Reserve, $440 \mathrm{~m}$ elevation, is located on the left bank of the River Claro. It consists of approximatly $2 \mathrm{~km}^{2}$ of primary tropical forest vegetation, and large rocks with calcareous surfaces lie along the valley floor (Pérez 1989). A tourist lodge, "El Refugio", has been built inside the forest. One family resides at the lodge year-round; animals consist of small coop of chickens.

The precipitation of The Rio Claro Valley from 1987 to 1989 consists of heavy rainfall from August to November, followed by a decrease rainfall from December to March. Another peak in precipitation occurs from April to June followed by short dry season during July. The average rainfall was $4,483 \mathrm{~mm} /$ year, ranging from $3,621 \mathrm{~mm}$ during 1987 to $5,896 \mathrm{~mm}$ in 1989 . For the period from 1986 to 1989 , the mean temperature and relative humidity were $25.6^{\circ} \mathrm{C}$ (range $18.9^{\circ}-34.6^{\circ} \mathrm{C}$ ) and $89 \%$ (range $83-95 \%$ ), respectively (Bernal et al. 1989).

Collection methods and sites - Sand flies were collected at night, from September 4-5 1991, using CDC light traps, Shannon traps, one hamsterbaited Disney trap and human bait. Representative sites associated with peridomestic and extradomestic habitats were selected for sampling.

Peridomestic habitats - In "El Refugio" a CDC trap was placed in the chicken house, at a distance of $5 \mathrm{~m}$ from the wooden lodge (Fig. 3, site C1). In La Mulata two CDC traps and two Shannon were placed in locations within $5 \mathrm{~m}$ of two houses (Fig. 3, sites $\mathrm{C} 3, \mathrm{C} 4$ ).

Extradomestic habitats - A CDC trap and a Disney trap were placed in the forest near an outcrop of rocks, at distance of $400 \mathrm{~m}$ from the wooden lodge (Fig. 3, site C2). The CDC and the Disney traps were placed at a height of $1.0 \mathrm{~m}$ and $0.2 \mathrm{~m}$, respectively, and operated between 18:00-06:00 hr. A Shannon trap was used between 18:00-21:00 hr. In peridomestic and extradomestic habitats sand fly collections using human bait were carried out between 18:00-21:00 hr.

Captured sand flies were put in vials containing $70 \%$ ethanol. All samples were subsequently transported to the Entomology Section of the Laboratory of Public Health of Medellín for species identification and mounting. Sand flies were identified to species, using characters described by Young (1979). Lu. longipalpis males possessed pale tergal abdominal spots on segment III and IV as described by Ward et al. (1983). 


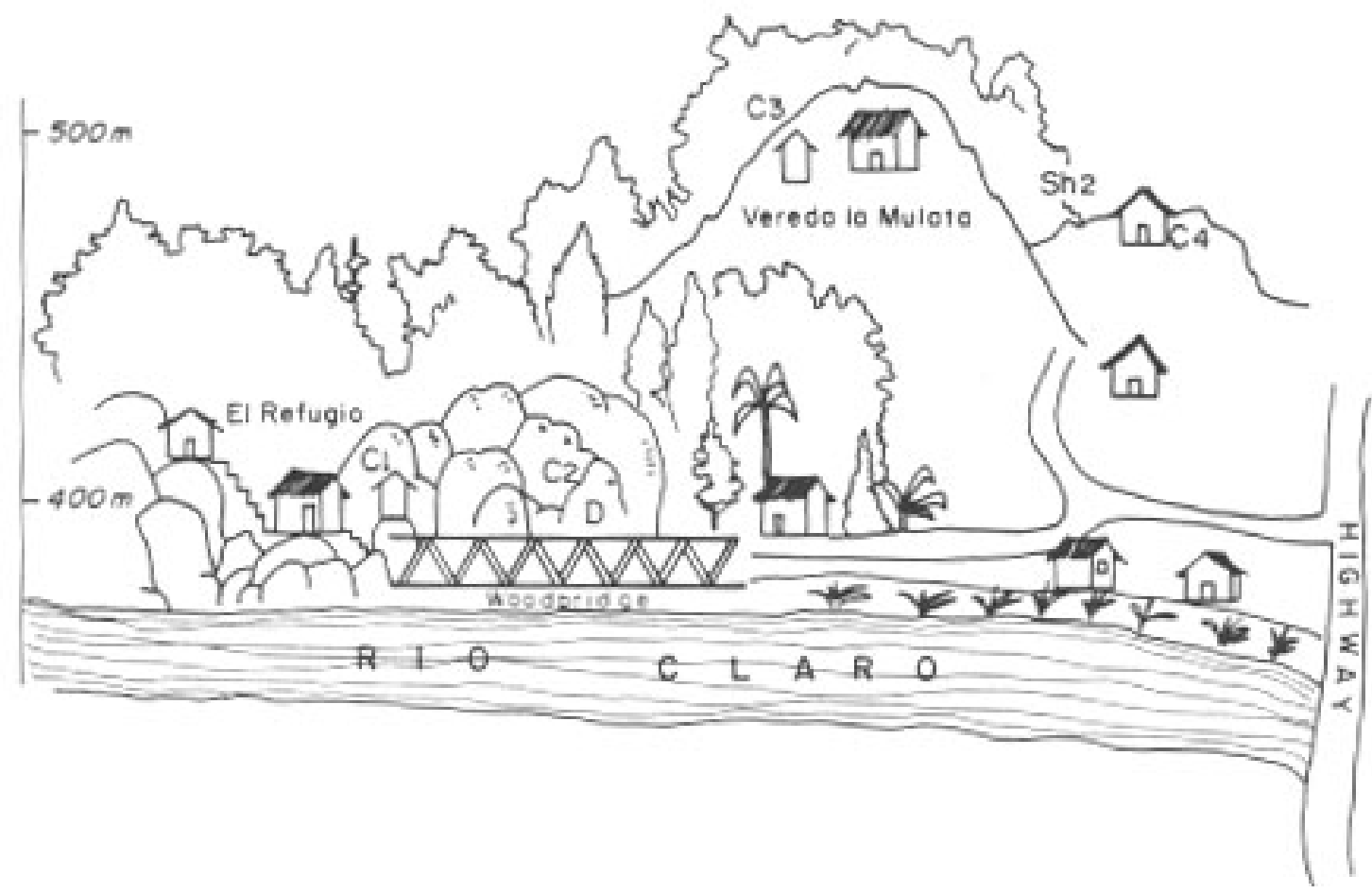

Fig. 3: scheme of trap location in the study. Sites C1, C2, C3 and C4.

TABLE

Phlebotominae collected according to trapping method, habitat and species in El Refugio and in La Mulata September 4-5, 1991

\begin{tabular}{|c|c|c|c|c|c|c|c|c|c|c|c|c|c|c|c|}
\hline \multirow{3}{*}{$\begin{array}{l}\text { Method of } \\
\text { capture } \\
\text { Habitat } \\
\text { Species }\end{array}$} & \multicolumn{4}{|c|}{ Human bait } & \multicolumn{4}{|c|}{$\begin{array}{l}\text { CDC Light } \\
\text { trap }\end{array}$} & \multicolumn{4}{|c|}{$\begin{array}{l}\text { Shannon } \\
\text { trap }\end{array}$} & \multirow{2}{*}{\multicolumn{2}{|c|}{$\begin{array}{l}\text { Disney } \\
\text { trap } \\
\text { Extra } \\
\end{array}$}} & \multirow[b]{3}{*}{ Total } \\
\hline & \multicolumn{2}{|c|}{ Peri } & \multicolumn{2}{|c|}{ Extra } & \multicolumn{2}{|c|}{ Peri } & \multicolumn{2}{|c|}{ Extra } & \multicolumn{2}{|c|}{ Peri } & \multicolumn{2}{|c|}{ Extra } & & & \\
\hline & $\mathrm{F}$ & M & $\bar{F}$ & M & $\mathrm{F}$ & $\bar{M}$ & $\bar{F}$ & $\bar{M}$ & $\mathrm{~F}$ & $\mathrm{M}$ & $\mathrm{F}$ & $\bar{M}$ & $\mathrm{~F}$ & $\bar{M}$ & \\
\hline Lu. longipalpis & - & - & - & - & 83 & 53 & 3 & - & 3 & - & - & - & - & - & 142 \\
\hline Lu. yuilli & 1 & - & 15 & - & 84 & 3 & 2 & - & 11 & 1 & 17 & 10 & - & - & 144 \\
\hline Lu. trapidoi & 1 & - & 2 & - & 14 & 1 & 3 & - & 3 & - & 7 & - & - & - & 31 \\
\hline Lu. hartmani & 1 & - & 20 & 1 & - & 6 & 1 & - & 1 & - & 1 & - & - & - & 31 \\
\hline Lu. triramula & - & - & - & - & 8 & 5 & 8 & - & 1 & - & 1 & 2 & - & - & 25 \\
\hline Lu. panamensis & - & - & 3 & - & 4 & 1 & 3 & - & 4 & 1 & 1 & - & - & - & 17 \\
\hline Lu. gomezi & 2 & - & 2 & - & 1 & 2 & - & - & 1 & - & 1 & - & - & - & 9 \\
\hline Lu. saulensis & - & - & - & - & 1 & - & 4 & - & - & - & 1 & - & - & - & 6 \\
\hline Lu. sordelli & - & - & - & - & 2 & - & - & - & - & - & 1 & - & - & - & 3 \\
\hline Lu. trinidadensis & - & - & - & - & 1 & - & 1 & - & 1 & - & - & - & - & - & 3 \\
\hline Lu. ovallesi & - & - & - & - & - & - & 1 & - & - & - & - & - & - & - & 1 \\
\hline Lu. carpenteri & - & - & - & - & 1 & - & - & - & - & - & - & - & - & - & 1 \\
\hline Lu. vespertilionis & - & - & - & - & - & - & - & - & - & - & - & - & - & 1 & 1 \\
\hline Lu. caprina & - & - & - & - & - & 1 & - & - & - & - & - & - & - & - & 1 \\
\hline Subg. Psathyromyia & - & - & - & - & - & - & - & - & - & - & 1 & - & - & - & 1 \\
\hline Subg. Pressatia & - & - & - & - & - & - & 1 & - & - & - & - & - & - & - & 1 \\
\hline B. galindoi & - & - & - & - & - & - & 1 & 1 & - & - & - & - & - & - & 2 \\
\hline Total & 5 & - & 42 & 1 & 199 & 72 & 28 & 1 & 25 & 2 & 31 & 12 & - & 1 & 419 \\
\hline
\end{tabular}

Lu: Lutzomyia; Peri: peridomestic; Extra: not associated with houses (forest); F: female; M: male. 


\section{RESULTS}

A total of 419 sand flies were collected in this survey, including 16 species of the genus Lutzomyia and 1 species of the genus Brumptomyia. Lu. longipalpis $(33.89 \%$ ) and $\mathrm{Lu}$. yuilli (Young \& Porter) $(34.37 \%)$ were the most abundant species (Table). More females than males were captured for Lu. longipalpis, Lu. yuilli, Lu. trapidoi (Fairchild \& Hertig) and Lu. hartmanni (Fairchild \& Hertig). Lu. longipalpis males were the most abundant.

Peridomestic habitat - Fourteen Lutzomyia species were colected. CDC ligh traps yielded mainly Lu. longipalpis and Lu. yuilli, while the Shannon trap yielded mainly Lu. yuilli (Table).

Extradomestic habitat - The CDC light trap and the Shannon trap yielded more species than other methods. $\mathrm{Lu}$. yuilli was the most abundant in the Shannon trap and $\mathrm{Lu}$. panamensis (Shannon)from the CDC light trap. Lu. yuilli and Lu. trapidoi were the two most abundant species collected with human bait. The Disney trap caught no sand flies (Table).

\section{DISCUSSION}

The ecological and demographical changes in Latin America have enhanced conditions for the successful colonization of Lu. longipalpis in regions where it had not been reported previously (Lainson 1989, Tesh 1995). Mark-realease-recapture studies of Lu. longipalpis shown it capable of moving 800-1000 m distances over short period of time. Also, they seem to move readily among cattle corrals at intermediate distances, suggesting that they are searching for food, mates or resting sites (Morrison et al. 1993). If available food determines the flight range of sandflies, as postulated by Alexander (1987), rural settlements along middle Magdalena Valley will move $L u$. longipalpis into the peridomestic environment. It is probable that this sand fly at present has a continuous distribution through the upper and middle Magdalena Valley but collections have only been carried out where cases of visceral leishmaniasis have been reported.

It has been suggested that $L u$. longipalpis populations represent a species complex (Ward et al. 1983, Lanzaro et al. 1993). Its members have been found in a variety of habitats (Lainson et al. 1990). The presence of this sand fly in Rio Claro may be due however to its invasin of the forest in association with man and his domestic animals rather than the existence of a native Lu. longipalpis population in forest environment.

Visceral leishmaniasis has not till now been reported in La Mulata and El Refugio, but from the standpoint of public health, the presence of its vector suggests a transmision risk of this disease within all the upper and middle Magdalena Valley, from Huila to canyon river in Rio Claro, Antioquia.

The trapping efficiency of CDC and Shannon traps is of practical importance in short term studies such as the present one for sampling of sand fly species, as is human bait for the anthropophilic species (Table). In this study, human bait collection in peridomestic and extradomestic habitats were negative for $L u$. longipalpis, although $\mathrm{Lu}$. hartmanni, Lu. trapidoi and Lu. yuilli were caught relatively abundantly in the extradomestic habitat. $L u$. hartmanni and Lu. trapidoi have been incriminated as vectors of $L$. panamensis and $L$. colombiensis respectively in Colombia (Young et al. 1987, Kreutzer et al. 1991). A few specimens of Lu. panamensis and Lu. gomezi (Nitzulescu) were also captured in this study. Both species are suspected as vectors of L. panamensis.

Further studies on the biochemical systematics and genetics try and genetics of $\mathrm{Lu}$. longipalpis populations are needed to establish the bounderies of species differences within this complex, as well as its relationship to other associated Lutzomyia species in the environment of the Magdalena Valley.

\section{ACKNOWLEDGEMENTS}

To Dr Amy Morrison, Dr Leonard Munstermann and Claribell Hernandez for their kind revision of the manuscript and valuable suggestions.

\section{REFERENCES}

Alexander JB 1987. Dispersal of phlebotomine sand flies (Diptera:Psychodidae) in a Colombian coffee plantation. J Med Entomol 24: 552-558.

Bernal GH, Montealegre E, Rangel E, Sabogal NA 1989. Estudio sobre el régimen de la precipitación en Colombia. Instituto Colombiano de Hidrología, Meteorología y Adecuación de Tierras (HIMAT). Bogotá, Colombia, 49 pp.

Cupolillo E, Grimaldi G, Momen H 1994. A general classification of New World Leishmania using numerical zymotaxonomy. Am J Trop Med Hyg 50: 296-311.

Corredor A, Kreutzer R, Tesh R, Boshell J, Palau MT, Cáceres E, Duque S, Peláez D, Rodríguez G, Nicholls S, Hernández C, Morales A, Ferro de Carrasquilla C 1990. Distribution and etiology of leishmaniasis in Colombia. Am J Trop Med Hyg 42: 206-214.

Espinal S 1978. Zonas de vida o formaciones vegetales de Colombia. Memoria explicativa sobre el mapa ecológico. Instituto Geográfico "Agustín Codazzi" (IGAC), $238 \mathrm{pp}$.

Ferro C, Morrison AC, Torres M, Pardo R, Wilson ML, Tesh RB 1995. Species composition and relative abundance of sand flies from the genus Lutzomyia 
(Diptera: Psychodidae) at an endemic focus of visceral leishmaniasis in Colombia. J Med Entomol 32: 527-537.

Grimaldi G, Tesh R, McMahon-Pratt D 1989. A review of geographic distribution and epidemiology of leishmaniasis in the new world. Am J Trop Med Hyg 41: 687-725.

Kreutzer RD, Corredor A, Grimaldi G, Grogl M, Rowton ED, Young DG, Morales A, McMahon-Pratt D, Guzmán H, Tesh RB 1991. Characterization of Leishmania colombiensis sp.n. Kinetoplastida: Trypanosomatidae), a new parasite infecting humans, animals, and phlebotomine sand flies in Colombia and Panama. Am J Trop Med Hyg 44: 662675.

Lainson R 1989. Demographic changes and their influence on the epidemiology of the American leishmaniases, p. 85-106. In MW Service, Demography and Vector-Borne Diseases. CRC Press, Boca Raton, FL.

Lainson R, Dye C, Shaw JJ, Macdonald DW, Courtenay O, Souza AA, Silveira FT 1990. Amazonian visceral leishmaniasis - Distribution of the vector Lutzomyia longipalpis (Lutz \& Neiva) in relation to the fox Cerdocyon thous (Linn.). The efficiency of this reservoir host as a source of infection. Mem Inst Oswaldo Cruz 85: 135-137.

Lanzaro GC, Ostrovska K, Herrero MV, Lawyer PG, Warburg A 1993. Lutzomyia longipalpis is a species complex: genetic divergence and interspecific hybrid sterility among three populations. Am J Trop Med Hyg 48: 839-847.

Momen H, Grimaldi G Jr, Deane LM 1987. Leishmania infantum, the aetiologic agent of American visceral leishmaniasis (AVL). Mem Inst Oswaldo Cruz 82: 447-448.

Morrison AC, Ferro C, Morales A, Tesh RB, Wilson ML 1993. Dispersal of the sand Lutzomyia longipalpis (Diptera: Psychodidae) at an endemic focus of visceral leishmaniasis in Colombia. $\mathrm{J} \mathrm{Med}$ Entomol 30: 427-435.

Pérez E 1989. Algunas características comportamentales y reproductivas del pájaro aceitero Steathormis caripiensis (Guácharo) en cuevas de la región de Puerto Triunfo. Thesis, Universidad de Antioquia, Medellín, Colombia, 70 pp.

Queiroz RG, Vasconcelos AW, Vasconcelos AB, Sousa RN, Alencar JE, David JR 1991. Phlebotomine sand fly Diptera:Psychodidae) fauna survey in an American cutaneous leishmaniasis (ACL) focus in Baturite, Ceará State, Northeast Brazil. Parassitologia 33 (Suppl. 1): 159-167.
Rangel EF, Azevedo ACR, Andrade CA, Souza NA, Wermelinger ED 1990. Studies on sandfly fauna (Diptera: Psychodidae) in a foci of cutaneous leishmaniasis in Mesquita, Rio de Janeiro State, Brazil. Mem Inst Oswaldo Cruz 85: 39-54.

Shaw JJ, Lainson R 1987. Ecology and epidemiology: New World, p.291-363. In W Peters \& R KillickKendrick, The Leishmaniases in Biology and Medicine, Vol 1, Academic Press, New York.

Tesh RB 1995. Control of zoonotic visceral leishmaniasis: Is it time to change strategies? Am J Trop Med Hyg 52: 287-292.

Travi Bl, Vélez ID, Brutus L, Segura I, Jaramillo CD, Montoya J1990. Lutzomyia evansi, an alternate vector of Leishmania chagasi in a Colombian focus of visceral leishmaniasis. Trans Soc Trop Med Hyg 84: 676-677.

Ward RD, Ribeiro AL, Ready PD, Murtagh A 1983. Reproductive isolation between different forms of Lutzomyia longipalpis (Lutz \& Neiva), (Diptera: Psychodidae), the vector of Leishmania donovani chagasi Cunha \& Chagas and its significance to kalaazar distribution in South America. Mem Inst Oswaldo Cruz 78: 269-280.

Ward RD 1985. Vector biology and control, p. 199-212. In KP Chang \& R Bray, Leishmaniasis. Elsevier Science Publishers, Amsterdam, New York \& Oxford.

Ward RD 1990. Some aspects of the biology of phlebotominae sandfly vectors, p.91-126. In RD Ward, Advances in disease vector research. Vol. 6. Springer-Verlag, New York.

Young DG 1979. A review of the bloodsucking psychodid flies of Colombia (Diptera: Phlebotominae and Sycoracinae). Tech. Bull. 806, Agric Exp Station, IFAS, Univ. Florida, Gainsville, FL.

Young DG, Morales A, Kreutzer RD, Alexander JB, Corredor A, Tesh RB, Ferro de Carrasquilla C, Rodríguez C 1987. Isolations of Leishmania braziliensis (Kinetoplastida: Trypanosomatidae) from cryopreserved Colombian sand flies (Diptera: Psychodidae). J Med Ent 24: 587-589.

Young DG, Duncan MA 1994. Guide to the identification and geographic distribution of Lutzomyia sand flies in Mexico, the West Indies, Central and South America (Diptera: Psychodidae). Mem Amer Entomol Inst 54: 1-881.

Zeledón R, Murillo J, Gutierrez H 1974. Observaciones sobre la ecología de Lutzomyia longipalpis y posibilidades de existencia de leishmaniasis visceral en Costa Rica. Mem Inst Oswaldo Cruz 79: 455459. 
